
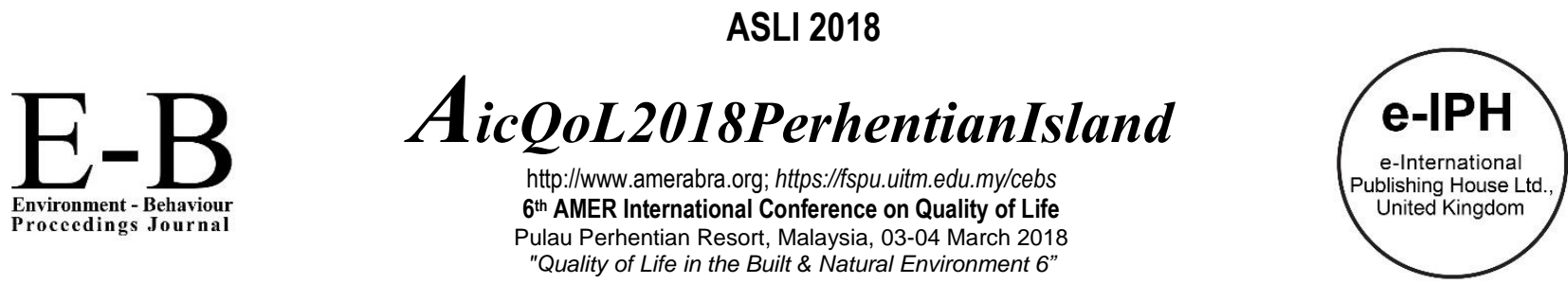

\title{
Orthorexia Nervosa and the Quality of Life among Health Sciences Students in Universiti Teknologi MARA, Selangor
}

\author{
Mohd Ramadan Ab Hamid¹, Nurfarhah Najwa Azman¹, Norimah Said², Aiman Nadia Akmar Rahman³ \\ ${ }^{1}$ Centre of Nutrition and Dietetics, \\ ${ }^{2}$ Centre of Nursing, \\ ${ }^{3}$ Centre of Physiotheraphy \\ Faculty of Health Sciences \\ Universiti Teknologi Mara, 42300 Bandar Baru Puncak Alam Selangor, Malaysia \\ ramadan7230@puncakalam.uitm.edu.my \\ Tel:+603-32584424
}

\begin{abstract}
Orthorexia Nervosa $(\mathrm{ON})$ is the obsession of an individual towards healthy foods. It has been shown to be related to quality of life (QoL). The aims of this study are to assess the prevalence of ON, QoL, and the correlation between ON and QoL. 138 students completed Orto-15 and WHOQOL-BREF questionnaires. $67.4 \%$ of the students had the tendency to experience ON. For Quality of Life, the psychological domain scored the highest (M=64.14, $S D=11.74)$, while the social domain was the lowest $(M=62.52, S D=11.41)$. There was a small correlation $(r<0.29)$ between Orthorexia Nervosa and the quality of life.
\end{abstract}

Keywords: 1; Orthorexia Nervosa, 2; Quality of Life, 3; University student

eISSN: 2398-42870 2018. The Authors. Published for AMER ABRA cE-Bs by e-International Publishing House, Ltd., UK. This is an open access article under the CC BYNC-ND license (http://creativecommons.org/licenses/by-nc-nd/4.0). Peer-review under responsibility of AMER (Association of Malaysian Environment-Behaviour Researchers), ABRA (Association of Behavioural Researchers on Asians) and cE-Bs (Centre for Environment-Behaviour Studies), Faculty of Architecture, Planning \& Surveying, Universiti Teknologi MARA, Malaysia.

DOI: https://doi.org/10.21834/e-bpj.v3i7.1264

\subsection{Introduction}

In recent years, people are very particular about healthy eating which supposedly has a positive impact on health. However, the obsession towards healthy foods causes a negative outcome in health and quality of life. This phenomenon is called Orthorexia Nervosa (ON). ON is a new concept among eating disorders (Malmborg, Bremander, Olsson, \& Bergman, 2017). It is an obsession towards quality rather than quantity of food. When obsession towards healthy eating becomes extreme, it causes psychological and social complications (Brytek-Matera, 2012). People with ON are particular about buying and preparing their foods. Unlike anorexia and bulimia, orthorexic may experience feelings of guilt and incompleteness without having healthy food. This is considered a harmful behaviour because healthy eating is connected with fear and worries about healthy foods. Also, people who experience ON prefer to fast or starve rather than eat all "impure" foods. Orthorexia Nervosa is considered a disorder due to the person having a specific attitude towards food by avoiding all foods that they consider harmful to their health. Increasing the prevalence of Orthorexia among students will negatively impact them because it can lead to malnutrition and unintentional weight loss (Malmborg et al., 2017). Malnutrition will affect the quality of life of students including physical, psychological, environmental, and social relations.

Quality of life refers to how individuals subjectively view the positive and negative aspects of their lives. It emphasizes both psychological and physical factors that collectively influence an individual's perception of the overall satisfaction with someone's life (Joseph, Royse, \& Pekmezi, 2014). Quality of life among university students, based on several studies, are in steep decline (Lins, Carvalho, Menezes, Porto-Silva, \& Damasceno, 2015; Lua, Dali, P, \& Shahril, 2012). The students have an increase in burden and

eISSN: 2398-4287@ 2018. The Authors. Published for AMER ABRA cE-Bs by e-International Publishing House, Ltd., UK. This is an open access article under the CC BYNC-ND license (http://creativecommons.org/licenses/by-nc-nd/4.0/). Peer-review under responsibility of AMER (Association of Malaysian Environment-Behaviour Researchers), ABRA (Association of Behavioural Researchers on Asians) and cE-Bs (Centre for Environment-Behaviour Studies), Faculty of Architecture, Planning \& Surveying, Universiti Teknologi MARA, Malaysia.

DOI: https://doi.org/10.21834/e-bpj.v3i7.1264 
responsibility, and may experience a lot of stressors once they enter university life. In fact, the latest trend shows that students are prone to choose a sedentary lifestyle, so they have more time to complete their assignments. (Abdullah \& Mohamad, 2016). Due to this, they may end up living an unhealthy lifestyle and are specifically likely to affect their good performance of quality of life. The initiation of negative health behaviours will increase the risk of emotional and psychological stress, which may negatively impact their quality of life.

Students in university are prone to develop ON and this may impair their quality of life. Assessment of ON and QoL and its correlation are paramount to ensure they are practicing a right and healthy lifestyle. However, studies regarding on the relationship between ON and QoL among healthy young adults and college students are still scarce. Therefore, the aims of this study are to determine the prevalence of ON, assess the QoL, and to identify the association between demographic profiles with ON and QoL.

\subsection{Methodology}

\subsection{Study Design and Sampling}

This cross-sectional study applied convenience sampling. 138 students from Faculty of Health Sciences, Universiti Teknologi MARA had participated in this study. Participants were between the ages of 18 to 25 years and Study full-time. Students presented with terminal disease and are bed-ridden were excluded.

\subsection{Socio-Demographic Characteristics}

All students completed a personal information form which comprises of demographic questions: gender, age, financial support, and residence. Height and Body weight were measured to determine the students' body mass index (BMI). Body weight was measured using an electronic scale to the nearest $0.1 \mathrm{~kg}$, whereas height was measured using a stadiometer attached to the electronic scale to the nearest $0.1 \mathrm{~cm}$. HBF-306 OMRON model body fat analyser was used to check the body fat percentage of the students.

\subsection{Orthorexia Nervosa}

The Orthorexia Nervosa questionnaire was used in this study. The questionnaire has been validated in another study (Donini, Marsili, Graziani, Imbriale, \& Cannella, 2005). The Orto-15 Questionnaire is a tool consisting of 15 items describing the intensification of the Orthorexia behaviour. Each item was assessed by a using Likert scale- always, often, sometimes, and never. A higher value of the test indicates closer to proper eating patterns. The test suggested being at a level of 40 cut-off points. Scores below 40 points in the ORTO15 test were classified as Orthorexia and eating behaviour reaches normal eating pattern as the score increases.

\subsection{Quality of life}

WHOQOL-BREF is a valid and reliable tool to assess QoL. The abbreviated version with 26 items is more acceptable by subjects. The response options range from 1 (very dissatisfied/ very poor) to 5 (very satisfied/ very good). The questionnaire contains 26 questions and includes four QoL domains: physical, psychological, environmental, and social relations. The mean score of items within each domain was used to calculate the domain score. The WHOQoL allows the authors to establish specific scores for each QoL domain which, after being standardized, vary from 0 (lowest QoL) to 100 points (highest QoL).

\subsection{Ethical approval \\ This study was approved by the UiTM ethical committee.}

\subsection{Statistical analysis}

The data obtained were analysed by using SPSS software version 21.0. Descriptive statistics for all demographic characteristics are presented as frequencies, percentages, means, and standard deviation or median (IQR). Q-Q plot was used to check the normality of the data. Descriptive statistics were used to measure the prevalence of Orthorexia Nervosa and the mean score of QoL domains. Pearson Chi-Square Test was used to compare the association between gender, courses, BMI, and body fat with ON. An independent t-test and ANOVA was used to compare mean score differences between groups of QoL. Correlation test was employed to find the strength of the association between $\mathrm{ON}$ and QoL. The categories of correlation are small (0.10-0.29), medium (0.30-0.49), and large $(0.50-1.00)$ based on Cohen, 1988. A value of $p<0.05$ was considered statistically significant.

\subsection{Results}

The demographic characteristics of students are presented in Table 1. A total of 138 students participated in the study. Majority of the students were female (88.4\%), Malay (97.1\%), single (98.6\%), stayed as UiTM residents $(87.7 \%)$, non-vegetarian $(98.6 \%)$, and nonsmoker (99.3\%). All subjects did not take alcohol (100\%). The mean (SD) age of all students were $21.8 \pm 1.48$ years, ranging from 19 to 25 years. Based on WHO, more than half of them (63.8\%) were within the desirable BMl range $(18.5-24.9) \mathrm{kg} / \mathrm{m}^{2}$. Their median (IQR) of BMI was $21.39(1.48) \mathrm{kg} / \mathrm{m}^{2}$. 
Table 1: Descriptive characteristics of the participants $(n=138)$

\begin{tabular}{lll}
\hline Characteristics & $\mathbf{n}(\%)$ & Mean \pm SD \\
\hline Gender & $16(11.6)$ & \\
Male & $122(88.4)$ & \\
Female & & \\
Age & $121(87.7)$ & \\
Residential & $15(10.9)$ & \\
UiTM Residential & $2(1.4)$ & \\
Rental House & & \\
Self-Property & $69(50)$ & \\
Financial Support & $43(31.2)$ & \\
Loans & $26(18.8)$ & \\
Scholarships & & \\
Self-Financed & $20(14.5)$ & \\
Body Mass Index $\left(\mathbf{k g} / \mathbf{m}^{2}\right)$ & $88(63.8)$ & \\
Underweight & $24(17.4)$ & \\
Normal & $6(4.3)$ & \\
Overweight & $7(5.1)$ & \\
Obese & $68(49.3)$ & \\
Body Fat (\%) & $38(27.5)$ & \\
Low & $25(18.1)$ & \\
Normal & & \\
Slightly High & & \\
High &
\end{tabular}

The result for the prevalence of $\mathrm{ON}$ is presented in Table 2. Majority students (67.4\%) had scored below 40 indicating they may experience $\mathrm{ON}$.

Table 2. Prevalence of Orthorexia Nervosa

\begin{tabular}{cc}
\hline ORTO-15 score & $\mathbf{n}(\%)$ \\
\hline$<40$ & $93(67.4)$ \\
$>40$ & $43(32.6)$ \\
\hline
\end{tabular}

Table 3 shows the association of demographic characteristics with ON. There is no significant difference between genders $x^{2}(1$, $\mathrm{N}=138), p=0.068$ and courses $x^{2}(1, N=138), p=0.649$ with ON. However, male students $(87.5 \%)$ are prone to experience ON compared to female $(64.8 \%)$. In relation to BMI, normal BMI $(73.9 \%)$ has a higher tendency for getting ON than underweight $(60 \%)$ and overweight $(53.5 \%)$ students. Slightly high body fat $(71.4 \%)$ is the highest proportion for tendency to obtain ON. On top of that, BMI shows that there is no significant difference on $\mathrm{ON} x^{2}(2, N=138), p=0.087$ and no significant difference between body fat and $\mathrm{ON} x^{2}(2, N=138)$, $p=0.599)$. Thus, fail to reject the null hypothesis.

Table 3: Association between gender, courses, BMI and body fat with Orthorexia Nervosa

\begin{tabular}{|c|c|c|c|c|}
\hline \multirow[t]{2}{*}{ Variables } & \multicolumn{2}{|c|}{ Orthorexia Category } & \multirow[t]{2}{*}{$\mathrm{X}^{2}$ Statistic (df) } & \multirow[t]{2}{*}{$p$-value } \\
\hline & $\begin{array}{c}\text { Orthorexia } \\
\mathrm{n}(\%)\end{array}$ & $\begin{array}{c}\text { Normal } \\
\mathrm{n}(\%)\end{array}$ & & \\
\hline \multicolumn{5}{|l|}{ Gender } \\
\hline Male & $14(87.5)$ & $2(12.5)$ & $3.330(1)$ & 0.068 \\
\hline Female & $79(64.8)$ & $43(35.2)$ & & \\
\hline \multicolumn{5}{|l|}{ BMI } \\
\hline Underweight & $12(60)$ & $8(40)$ & $4.873(2)$ & 0.087 \\
\hline Normal & $65(73.9)$ & $23(26.1)$ & & \\
\hline Overweight & $16(53.3)$ & $14(46.7)$ & & \\
\hline \multicolumn{5}{|l|}{ Body Fat } \\
\hline Low & $4(57.1)$ & $3(42.9)$ & $1.025(2)$ & 0.599 \\
\hline Normal & $44(64.7)$ & $24(35.3)$ & & \\
\hline Slightly High & $45(71.4)$ & $18(28.6)$ & & \\
\hline
\end{tabular}

* Pearson Chi-Square Test

In terms of QoL, Table 4 indicates the QoL scores for four domains. Psychological health score was $64.1(\mathrm{SD}=11.7)$, physical domain was $63.1(S D=10.4)$, environmental domain was $63.1(S D=10.8)$, and social domain was $62.5(S D=14.6)$

Table 4: Quality of Life $(n=138)$

\begin{tabular}{clc}
\hline Quality of life domain & Mean (SD) \\
\hline - & Physical & $63.13(10.43)$ \\
- & Psychological & \\
- & Envial & $64.14(11.74)$ \\
& $62.52(14.59)$ \\
\end{tabular}


Table 5 shows the association of Gender, BMI, and Body Fat with Quality of Life (QoL). Result show that female participants achieved higher scores over males in all domains with physical score $(M=63.48, S D=10.22)$, psychological $(M=64.39, S D=11.41)$, social relation $(M=62.98, S D=14.94)$, and environment $(M=63.48, S D=11.11)$. Meanwhile, for $B M I$, overweight students scored the lowest in physical $(M=60.37, S D=9.32)$, psychological $(M=61.7, S D=13.95)$, and social domains $(M=63.3, S D=7.81)$. Students who have slightly high body fat also got a lower score in the physical $(M=62.19, S D=10.26)$ and psychological domains $(M=62.87, S D=9.87)$ than low and normal body fat. However, there was no significant mean difference between sexes, courses, BMI, and body fat in all QoL domains.

Table 5: Mean of Gender, BMl and Body Fat with Quality of Life (QoL) ( $n=138)$

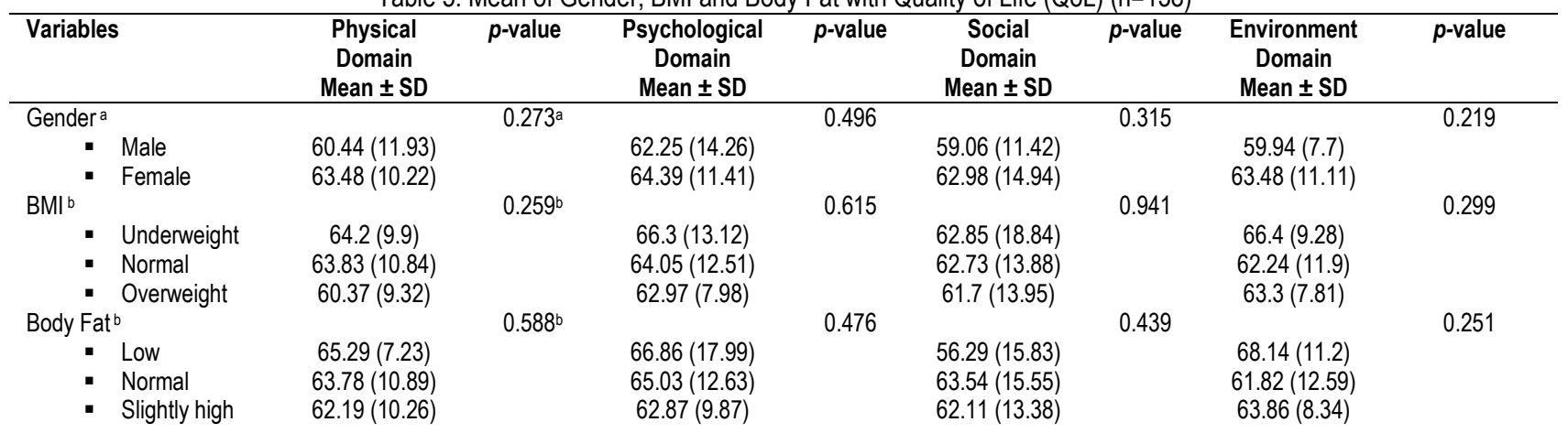

ap- value obtain from Independent t-test

bp-value obtain from ANOVA test

Table 6 indicates the correlation between orthorexia nervosa and quality of life. Overall, there was small correlation $(r<0.29)$ between the variables. Increase in Orthorexia scores positively correlated with physical $(r=0.175, p=0.04)$ and psychological $(r=0.029, p=0.731)$ domain scores. However, the orthorexia scores inversely correlated with social $(r=-0.221, p=0.009)$ and environmental $(r=-0.130$, $\mathrm{p}=0.129$ ) domain scores.

Table 6. Correlation between Orthorexia Nervosa Scores and Quality of Life $(n=138)$

\begin{tabular}{|c|c|c|c|c|c|c|c|c|}
\hline Variables & $\begin{array}{c}\text { Physical } \\
\text { Domain } \\
r\end{array}$ & $p$-value & $\begin{array}{c}\text { Psychological } \\
\text { Domain } \\
r\end{array}$ & $p$-value & $\begin{array}{c}\text { Social } \\
\text { Domain } \\
r\end{array}$ & $p$-value & $\begin{array}{c}\text { Environment } \\
\text { Domain } \\
r\end{array}$ & $p$-value \\
\hline Orthorexia Nervosa & 0.175 & 0.04 & 0.029 & 0.731 & -0.221 & 0.009 & -0.130 & 0.129 \\
\hline
\end{tabular}

\subsection{Discussion}

In the present study, the prevalence of Orthorexia Nervosa (67.4\%) among undergraduate health science students was investigated. The possible factor for the high prevalence is that the health science students may have highly sensitive behaviour towards healthy and proper nutrition (Bağci Bosi, Çamur, \& Güler, 2007).

According to Koven and Abryy (2015), the previous literature showed inconsistent findings in terms of gender and Orthorexia Nervosa. Some studies reported that the rates of Orthorexia were higher men than women, whereas other studies reported the reverse pattern. In the present study, the result is similar to Bağci Bosi et.al (2007), in which the ORTO-15 score is more prevalent among male students $(87.5 \%)$ compared to female $(64.8 \%)$. However, there is no statistically significant difference between gender and ON. Males are prone to get $\mathrm{ON}$ due to their eagerness towards maintaining their body shape and being very particular about quality of eating lifestyle. Caution must be given to the findings as there were unequal distributions of female and male participants, likely due to female predominance in health science courses in university. Supposedly, people with more education on healthy nutrition are more likely to be concerned and affixed on eating healthy foods. Nevertheless, the current study shows the inversed result. There was a research study that was similar to the present study, which found that nutritional students did not show higher ON tendency compared to students from other disciplines (Missbach et.al, 2015).

Body fat and BMI also show no significant differences on "health fanaticisim". In line with the previous study by Bağci Bosi et al., (2007), no differences between BMI and ON were found. The possible explanation is that "health fanaticisim" depends on the healthy eating knowledge that an individual has, and not necessarily on their BMI or body fat. The higher the health knowledge, the higher the tendency to become ON (Fidan et al., 2014). In contrast, according to Stochel et.al (2013) and Missbach et al., (2017), Orthorexia diagnosis is more likely among overweight and obese young people.

A study was done by Feder et al., (2015) on the subject and achieved the lowest score among participants in the psychological domain $(M=15.99, S D=2.43)$ while the highest was in the environmental domain $(M=16.67, S D=2.2)$. However, the result contradicts with the present study. The result in the present study reveals the highest mean score is for the psychological health domain ( $M=64.14$, $S D=11.74)$, while the lowest mean score is for the social domain $(62.52, S D=14.59)$. In contrast with previous literature, health sciences students may find enjoyment and satisfaction in university, thus, performing well in their psychological relation (Bakar, 2012). On the other hand, they are lacking in social relationships due to their packed schedule for classes, labs, and co-curricular activities in the 
university. On top of that, most of the students want to maintain established networks among their friends in the limited time condition they are in. This may lead them to have a poor interpersonal relationship (Christine, Trent, \& Kingdom, 2010).

Demographic variables such as gender and courses may relate to QOL. However, the current findings are not consistent. The current study did not reveal significant differences between sexes and all domains of QoL. Although there is no significant mean difference, the current study shows that the mean score for each domain was higher in females than males. Current findings indicate students with slightly high body fat score the lowest in the physical and psychological domains. On the other hand, overweight students showed the lowest score in physical, psychological, and social domains. It could be due to the feeling of insecurity about their body image, causing them to have low self-esteem and socialize less with others (Press, 2015).

The correlation between ON and QoL was small $(r<0.29)$. ON was found to be inversely correlated with social $(r=-0.221)$ and environmental $(r=-0.130)$ domains for $Q \mathrm{oL}$. It indicates that the more individuals have tendency to experience ON, it reduced their social activity and connection with the environment.

Cross-sectional design studies have intrinsic limitations and one of them is the difficulty in establishing the temporal relationship between dependent and independent variables. The second limitation is the sample was imbalanced between genders, due to the recruitment of more females than males as respondents; hence, the results were heavily biased towards females. This is due to a higher proportion of female students in the health sciences faculty, which represents a common trend in universities in Malaysia. However, the strength of this study is that it is less biased as the anthropometry measurements are taken by using appropriate tools and not just simply self-reported by participants. The other strength is that the current study is one of the few studies in which the relationship between $\mathrm{ON}$ and QoL has been examined in a population of healthy undergraduates.

\subsection{Conclusion}

This study provides the baseline data on Orthorexia Nervosa and Quality of life among students. Current prevalence indicates that a majority of students have the tendency to develop ON. Although health sciences students should have a positive eating behaviour and good quality of life, this study indicates the reverse. Therefore, it is vital to disseminate the correct information about healthy eating practices via nutrition education programmes in the university.

\section{Acknowledgements}

The authors would like to thank all the parties, especially participants, for their co-operation throughout data collection.

\section{References}

Abdullah, N., \& Mohamad, N. (2016). University Recreational Facilities Service Quality and Students' Physical Activity Level. Procedia - Social and Behavioral Sciences, 224(August 2015), 207-212. https://doi.org/10.1016/j.sbspro.2016.05.443

Bağci Bosi, A. T., Çamur, D., \& Güler, Ç. (2007). Prevalence of orthorexia nervosa in resident medical doctors in the faculty of medicine (Ankara, Turkey). Appetite, 49(3), 661-666. https://doi.org/10.1016/j.appet.2007.04.007

Bakar, A. (2012). Health-Related Quality of Life among Youth : Evaluating Measurement Model Fit, 2(3), 9-12.

Brytek-Matera, A. (2012). Orthorexia nervosa - An eating disorder, obsessive-compulsivedisorder or disturbed eating habit? Archives of Psychiatry and Psychotherapy, 14(1), 55-60.

Christine, H., Trent, N., \& Kingdom, U. (2010). The Social Life of Students : support mechanisms at university.

Cohen, J. (1988). Set Correlation and Contingency Tables. Applied Psychological Measurement. 12 (4).

Dittfeld, A., Gwizdek, K., Koszowska, A., Nowak, J., Brończyk-puzoń, A., Jagielski, P., ... Zdrowia, W. (2016). Assessing the Risk of Orthorexia in Dietetic and Physiotherapy Students Using the BOT (Bratman Test for Orthorexia ) Ocena ryzyka ortoreksji wśród studentów dietetyki i fizjoterapii z użyciem BOT ( Bratman Test for Katedra i Zakład Histologii i Embriologii , Wydział Lekarski z Oddziałem Lekarsko-Dentystycznym w Za-, 6-14. https://doi.org/10.18544/PEDM-22.01.0044

Donini, L. M., Marsili, D., Graziani, M. P., Imbriale, M., \& Cannella, C. (2005). Orthorexia nervosa : Validation of a e c i $r$ t i s i t e, 10(June). Duèinskienë, D., \& Kalëdienë, R. (2003). Quality of Life among Lithuanian University Students, (2).

Feder, K., Michaud, D. S., Keith, S. E., Voicescu, S. A., Marro, L., Than, J., ... Berg, F. Van Den. (2015). An assessment of quality of life using the WHOQOL-BREF among par- ticipants living in the vicinity of wind turbines \$. Environmental Research, 142, 227-238. https://doi.org/10.1016/j.envres.2015.06.043

Fidan, T., Ertekin, V., Isikay, S., Kaya, D., Esin, I., \& Asfuroglu, B. (2014). P.7.f.004 Orthorexia nervosa and education. European Neuropsychopharmacology, 24(5), S731. https://doi.org/10.1016/S0924-977X(14)71177-0

Joseph, R. P., Royse, K. E., \& Pekmezi, D. W. (2014). Mediators, 23(2), 659-667. https://doi.org/10.1007/s11136-013-0492-8.Physical

Koven, N. S., \& Abryy, A. W. (2015). The clinical basis of orthorexia nervosa : emerging perspectives, 385-394.

Lins, L., Carvalho, F. M., Menezes, M. S., Porto-Silva, L., \& Damasceno, H. (2015). Health-related quality of life of students from a private medical school in Brazil. International Journal of Medical Education, 6, 149-154. https://doi.org/10.5116/ijme.563a.5dec 
Lua, P. L., Dali, W., P, W., \& Shahril, M. (2012). Nutrition Quality of Life among Female- Majority Malay Undergraduate Students of Health Sciences. Malaysian Journal of Medical Sciences, 19(4), 38-50.

Malmborg, J., Bremander, A., Olsson, M. C., \& Bergman, S. (2017). Health status, physical activity, and orthorexia nervosa: A comparison between exercise science students and business students. Appetite, 109, 137-143. https://doi.org/10.1016/j.appet.2016.11.028

Missbach, B., Dunn, T. M., \& König, J. S. (2017). We need new tools to assess Orthorexia Nervosa. A commentary on \&quot;Prevalence of Orthorexia Nervosa among College Students Based on Bratman's Test and Associated Tendencies\&quot;. Appetite, 108, 521-524. https://doi.org/10.1016/j.appet.2016.07.010

Missbach, B., Hinterbuchinger, B., Dreiseitl, V., \& Zellhofer, S. (2015). When Eating Right, Is Measured Wrong ! A Validation and Critical Examination of the ORTO-15 Questionnaire in German, 1-15. https://doi.org/10.1371/journal.pone.0135772

Press, D. (2015). Weight status and body image perceptions in adolescents : current perspectives, 149-158.

Stochel, M., Hyrnik, J., Jelonek, I., Zejda, J., \& Janas-Kozik, M. (2013). Orthorexia among Polish urban youth. European Neuropsychopharmacology, 23(2), 527-528. https://doi.org/10.1016/S0924-977X(13)70837-X

Unni, E. J., Madrid, L., Oderda, G., \& Saokaew, S. (2015). Quality of life of pharmacy students in the United States. Currents in Pharmacy Teaching and Learning, 7(6), 753-763. https://doi.org/10.1016/j.cptl.2015.08.007

Zhang, Y., Qu, B., Lun, S., Wang, D., Guo, Y., \& Liu, J. (2012). Quality of Life of Medical Students in China: A Study Using the WHOQOL-BREF, 7(11). https://doi.org/10.1371/journal.pone.0049714 